JKEP

Vol 6, No 1 (2021)

ISSN: 2354-6042 (Print)

ISSN : 2354-6050 $\underline{\text { (Online })}$

\title{
Hubungan Kemampuan Mobilisasi dengan Risiko Jatuh Pada Lansia Hipertensi
}

\author{
Sinta Kholifah Mar'ah Konitatillah ${ }^{1}$, Latifa Aini Susumaningrum ${ }^{1}$, Hanny \\ Rasni ${ }^{1}$, Tantut Susanto ${ }^{1}$, Roro Dewi ${ }^{2}$ \\ ${ }^{1}$ Fakultas Keperawatan, Universitas Jember, Jember \\ ${ }^{2}$ Unit Pelaksana Teknis Panti Sosial Tresna Werdha (UPT PSTW) Bondowoso \\ E-mail:tantut_s.psik@unej.ac.id
}

\author{
Artikel history \\ Dikirim, Jan $29^{\text {th }}, 2020$ \\ Ditinjau, Apr $12^{\text {th }}, 2021$ \\ Diterima, Apr $20^{\text {th }}, 2021$
}

\begin{abstract}
Hypertensive elderly influences body balance that affects their ability to mobilize. Therefore, this condition can improve a risk for falling. The aimed of this study was to analyzed the relationship between mobilization ability and risk for fall among elderly with hypertension in Tresna Werdha Social Services (PSTW) Bondowoso. A cross sectional design was conducted among 47 elderly using total sampling. A selfadministered questionnaire was used to measure sociodemographic of elderly, while Elderly Mobility Scale (EMS) was performed to measure mobilization ability and Morse Falls Scale was performed to measure risk for fall. The relationship mobilization ability and risk for fall was analysed using Chi Square test. The result showed that among 47 elderly were 49,8\% of independent and 46,8\% of low risk for falling. There were significantly relationship between mobilization ability and risk for fall $\left(X^{2}=14,674 ; p\right.$ $=0.001)$. The conclusion of this study, there is a relationship between mobilization ability and risk of fall among elderly. Therefore, elderly should be active in physical activities to reduce the risk of falling.
\end{abstract}

Keywords: Mobility; elderly; risk for fall.

\begin{abstract}
ABSTRAK
Lansia hipertensi mengalami penurunan keseimbangan tubuh yang mempengaruhi kemampuan mobilisasi mereka, sehingga mereka dapat berisiko jatuh Tujuan dari penelitian ini adalah untuk menganalisis hubungan antara mobilisasi kemampuan dan risiko jatuh di antara hipertensi lansia di Tresna Werdha Social Services Bondowoso. Desain cross sectional dilakukan di antara 47 lansia menggunakan total sampling. Kuesioner yang dikelola sendiri digunakan untuk mengukur sosiodemografi orang tua, sementara Skala Mobilitas Lansia (EMS) dilakukan untuk mengukur kemampuan mobilisasi dan Skala Morse Falls dilakukan untuk mengukur risiko jatuh. Kemampuan mobilisasi hubungan antara risiko jatuh menggunakan uji chi square. Hasil penelitian
\end{abstract}


menunjukkan 47 lansia adalah 49,8\% independen, sedangkan 46,8\% risiko rendah jatuh. Ada hubungan yang signifikan antara kemampuan mobilisasi dan risiko jatuh (x2 $=14.674 ; \mathrm{p}=0,001)$. Kesimpulan dari penelitian ini, ada hubungan antara mobilisasi kemampuan dan risiko jatuh di kalangan lansia. Karena itu, lansia harus aktif dalam kegiatan fisik untuk mengurangi risiko jatuh.

Kata Kunci: kemampuan mobilisasi; lansia; risiko jatuh

\section{PENDAHULUAN}

Proses menua membuat seseorang dewasa yang ada pada keadaan sehat menjadi seorang yang lemah dan rentan, dengan berkurangnya sebagian besar cadangan sistem fisiologis dan lebih rentan terhadap berbagai macam penyakit serta kematian secara eksponensial (Susanto, 2013). Penyakit yang dapat dialami seorang saat berusia lanjut adalah hipertensi, hal itu disebabkan karena elastisitas arteri yang mengalami penurunan sehingga tekanan darah cenderung meningkat (Seke dkk., 2016). Apabila hipertensi tidak mendapatkan penanganan yang tepat maka akan menyebabkan masalah lebih banyak pada lansia. Peningkatan tekanan darah pada lansia mempengaruhi perfusi ke jaringan tubuh diantaranya yaitu otak sebagai pusat pengatur keseimbangan tubuh dan kesadaran seseorang. Akibat dari penurunan perfusi ke otak akan menyebabkan penurunan keseimbangan tubuh (Black dan Hawks, 2013). Kondisi penurunan keseimbangan tersebut memungkinkan timbulnya perubahan gaya berjalan (Edelman dan Ficorelli, 2012 dalam Yan dkk., 2019). Proses tersebut membuat lansia cenderung menjadi pasif atau cenderung tidak melakukan mobilisasi sehingga dapat berisiko untuk mengalami penurunan kekuatan otot yang kemungkinan dapat menimbulkan risiko jatuh.

Risiko jatuh menjadi penyebab ke dua kematian terbesar di dunia (WHO, 2018). Kondisi terkait kardiovaskuler berkontribusi terhadap ketidakmampuan beraktivitas fisik dan keterbatasan mobilisasi. Mobilitas merupakan prediktor terkuat terhadap risiko jatuh pada lansia (Anggarani, 2018). Namun dalam penelitian lain menyatakan riwayat jatuh yang pernah dialami menyebabkan lansia menurunkan tingkat aktifitas fisiknya secara optimal, sehingga lansia cenderung pasif (Yan dkk., 2019). Dampak fisiologis dari imobilisasi dan perilaku tidak aktif lansia yaitu lansia akan mengalami penurunan massa otot sebanyak 3\% perhari, yang akan berpengaruh pada kekuatan otot 
dan keseimbangan postural (Potter dan Perry, 2010). Perubahan keseimbangan postural akibat penurunan perfusi ke jaringan otak dapat menyababkan penurunan kemampuan mobilisasi pada lansia akan dapat menyebabkan jatuh pada lansia dengan hipertensi Setiap tahun diperkirakan ada sebanyak 646.000 orang yang meninggal akibat kejadian jatuh secara global, dimana lebih dari $80 \%$ kejadian jatuh tersebut terdapat di negara berpenghasilan menengah dan rendah. Lansia yang berusia 65 tahun keatas adalah populasi utama yang rentan jatuh. 37,3 juta orang jatuh cukup parah sehingga membutuhkan penanganan medis, hal ini terjadi setiap tahunnya (WHO, 2018). Berdasarkan hasil studi penelitian sebelumnya didapatkan sebanyak 90 lansia di UPT PSTW Bondowoso dan 34 (42\%) diantaranya memiliki risiko jatuh tinggi, dan 19 (23,8\%) memiliki risiko jatuh sedang (Riskiana, 2019). Angka kejadian jatuh dan angka lansia berisiko jatuh diatas tergolong sangat tinggi sehingga perlu dikaji mendalam dan perlu disusun intervensi untuk mengatasi tingginya angka kejadian dan angka risiko jatuh tersebut.
Angka kesakitan penduduk lansia tahun 2014 sebesar 25,99\% artinya bahwa dari setiap 100 orang lansia terdapat 25 sampai 26 orang di antaranya mengalami sakit (Kementrian Kesehatan RI, 2016). Penyakit yang banyak diderita lansia salah satunya yaitu hipertensi. Sebab faktor risiko hipertensi salah satunya adalah berusia lebih dari 65 tahun. Diperkirakan 1,13 miliar orang diseluruh dunia menderita hipertensi, dan dua pertiga dari jumlah tersebut tinggal di negara dengan penghasilan menengah dan rendah. Hipertensi juga merupakan penyebab terbanyak kematian premature di dunia (WHO, 2019). Hipertensi banyak terjadi pada usia 35-44 tahun $(6,3 \%)$, usia $45-54$ tahun $(11,9 \%)$, dan usia 55-64 tahun (17,2\%) (Kemenkes RI, 2017). Penelitian sebelumnya menyebutkan bahwa penuaan dan hipertensi berhubungan dengan penurunan akselerasi kardio dan vasokonstriksi yang dimediasi barorefleks, gangguan konservasi garam dan air ginjal, dan pengisian jantung lambat. Penurunan ortostatik akut pada tekanan darah penderita hipertensi dapat menyebabkan iskemia serebral transien dari aliran darah yang berkurang ke otak, yang dapat memperburuk penurunan kronis aliran darah otak (Gangavati dkk., 
2012). Timbulnya penurunan perfusi ke jaringan otak dapat mempengaruhi tingkat keseimbangan bahkan kesadaran. Hal tersebut memungkinkan lansia yang mengalami hipertensi akan mengalami perubahan keseimbangan dan selanjutnya menyebabkan jatuh (Black dan Hawks, 2013). Hal tersebut sangat berbahaya bagi lansia, karena salah satu komplikasi yang timbul akibat terjatuh adalah kematian (Murtiani dan Suidah, 2019).

Dampak fisiologis dari imobilisasi dan ketidakaktifan salah satunya adalah peningkatan katabolisme protein sehingga menyebabkan penurunan kekuatan otot (Uda dkk., 2016). Tubuh dapat bereaksi secara fisiologis terhadap kejadian imobilisasi dengan timbulnya perubahan-perubahan yang tidak jauh beda dengan proses menua pada lanjut usia, oleh karena itu dapat memperberat efek penuaan yang sedang berlangsung. Akibat perubahan fisik lansia tersebut akan menyebabkan terjadinya risiko jatuh pada lansia (Stanley \& Beare, 2012). Menurut data Riskesdas 2015 terdapat peningkatan kejadian jatuh sebanyak $40,9 \%$ baik yang mengakibatkan cedera dan tidak menyebabkan cedera (Riset Kesehatan Dasar, 2015).

Risiko jatuh akan sangat berbahaya bagi lansia mengingat komplikasi yang mungkin timbul akibat terjatuh. Penelitian sebelumnya menyebutkan bahwa gangguan keseimbangan postrural menjadi salah satu penyebab terjadinya jatuh pada lanjut usia yang dapat menyebabkan patah tulang, keseleo pada otot, perlukaan jaringan bahkan jatuh dapat menyebabkan kematian pada lansia (Murtiani dan Suidah, 2019). Oleh karena itu tujuan penelitian ini untuk menganalisis hubungan antara kemampuan mobilisasi dan risiko jatuh pada lansia hipertensi di UPT PSTW Bondowoso.

Penelitian ini sangat penting untuk dilakukan guna mengetahui apakah tingkat kemampuan mobilisasi dapat berhubungan dengan risiko jatuh pada lansia dengan hipertensi. Sebelumnya telah terdapat penelitian oleh (Yan dkk., 2019)yang menganalisa hubungan antara pengalaman jatuh dan kejadian imobilisasi pada lansia namun tidak focus pada lansia dengan hipertensi sehingga peneliti ingin menunjukkan bagaimana kemampuan mobilisasi lansia 
dengan hipertensi dapat berhubungan dengan risiko jatuh yang kemungkinan dialami. Sehingga dalam proses perawatan lansia dapat disertakan latihan keseimbangan guna mencegah imobilisasi dan risiko jatuh pada lansia hipertensi.

\section{METODE}

Penelitian ini menggunakan desain korelasi dengan pendekatan cross sectional (Desember, 2019). Subjek penelitian sebanyak 47 lansia dari 94 lansia di UPT PSTW Bondowoso menggunakan total sampling. Sampel yang dipilih adalah lansia yang memenuhi kriteria inklusi penelitian. Kriteria inklusi yaitu lansia dengan hipertensi grade 1 dan 2 yang menetap di UPT PSTW Bondowoso dan bersedia menjadi responden. Kriteria eksklusi penelitian ini yaitu lansia yang tergolong hipertensi grade 3, memiliki gangguan fisik dan mental yang mempengaruhi penelitian ini, memiliki skor Mini mental State Exam (MMSE) <21.

Awalnya peneliti melakukan penapisan dengan memilah data lansia yang didapatkan dari staf UPT PSTW Bondowoso. Sebanyak 23 lansia mengalami Orang Dengan Gangguan
Jiwa (ODGJ) dan Orang Dengan Masalah Kejiwaan (ODMK). Penapisan fisik yang dilakukan saat bertemu langsung dengan lansia didapatkan 3 lansia tergolong hipertensi grade 3, 2 orang lansia memiliki nilai MMSE $<21$, 17 lansia tidak tergolong hipertensi, dan saat penelitian 2 orang lansia tidak bersedia menjadi responden.

Sebelum pengambilan data, peneliti menjelaskan maksud, tujuan dan meminta persetujuan penelitian pada Kepala UPT PSTW Bondowoso, perawat dan responden. Lansia diminta mengisi kuesioner karakteristik, selanjutnya peneliti mengambil data nilai fungsi kognitif menggunakan MMSE, sebanyak 2 lansia memiliki skor $<21$ sehingga tidak dijadikan responden. Setelah dilakukan penapisan, sebanyak 47 lansia dikeluarkan dari penelitian sehingga total sampel dalam penelitian ini sebanyak 47 lansia. Karakteristik responden didata menggunakan kuesioner karakteristik responden yang terdiri atas kode responden, nama, usia, jenis kelamin, jenis perawatan, alat bantu berjalan dan riwayat jatuh. Variabel kemampuan mobilisasi diukur dengan kuesioner EMS yang telah diuji validitas dan realibilitasnya oleh Smith et al. 
(1994) validitas diukur dengan concurrent validity didapatkan $p$ value $=$ 0,948 dan realibilitas didapatkan $p$ value $=0,75$ (Smith, 1994). Setiap indikator dalam kuesioner EMS dapat dinilai dengan mengobservasi kemampuan lansia duduk, berdiri, berbaring, berjalan dan meraih benda secara langsung. Skor dalam penilaian kemampuan mobilisasi <10 ketergantungan, 10-13 parsial, >14 mandiri.

Variabel risiko jatuh diukur dengan kuesioner MFS yang telah diuji validitas dan realibilitasnya oleh Ediawati (2012) validitas didapatkan nilai $\mathrm{p}=0,499$ dan nilai realibilitas $\mathrm{p}=0,402$ (Ediawati, 2012). Instrumen MFS terdiri dari 6 indikator terdiri dari riwayat jatuh 3 bulan terakhir, diagnosa sekunder, alat bantu berjalan, terapi intravena, gaya berjalan dan status mental. Rentang skor 0-24 tidak berisiko jatuh, 25-50 berisiko jatuh rendah dan $>51$ berisiko jatuh tinggi .

Analisis data dilakukan dengan perangkat lunak SPSS versi 20. Uji normalitas data menggunakan uji Kolmogorov -Smirnov. Uji univariat skor total kemampuan mobilisasi dan risiko jatuh dilakukan dengan uji one sample Kolmogorov-Smirnov. Analisis bivariate menggunakan uji Chi Square untuk menguji hipotesis. Interval kepercayaan yang digunakan yaitu $95 \%$ sehingga apabila nilai $\mathrm{p}<0,05$ dinyatakan bermakna secara statistik. Penelitian ini telah mendapat izin etik Fakultas Kedokteran Gigi Universitas Jember dengan nomor

651/UN25.8/KEPK/DL/201

\section{HASIL DAN PEMBAHASAN}

Sebagian besar lansia berada pada usia pre lansia $(31,9 \%)$ dan paling banyak berjenis kelamin laki - laki (63,8\%). Sebagian besar lansia di UPT PSTW Bondowoso mandiri dalam memuhi aktivitas sehari - hari $(31,9 \%)$ sehingga lansia tidak membutuhkan alat bantu berjalan untuk melakukan aktivitas sehari - hari, karena lansia mandiri dan tidak pernah menggunakan alat bantu berjalan maka lansia tidak pernah mengalami jatuh $(59,6 \%)$. 
Tabel 1. karakteristik responden

\begin{tabular}{lc}
\hline \multicolumn{1}{c}{ Karakteristik Lansia } & $\mathrm{n}(\%)$ \\
\hline Usia & $8(17,0)$ \\
$60-64$ tahun & $14(29,8)$ \\
$65-69$ tahun & $15(31,9)$ \\
$70-74$ tahun & $10(21,3)$ \\
$>75$ tahun & \\
Jenis kelamin & $30(63,8)$ \\
Laki-laki & $17(36,2)$ \\
Perempua & \\
n & \\
Jenis perawatan & $3(6,4)$ \\
Tergantung total & $2(4,3)$ \\
Tergantung paling & $4(8,5)$ \\
berat Tergantung & 10 \\
berat Tergantung & $(21,3)$ \\
sedang Tergantung & 10 \\
ringan & $(21,3)$ \\
Tergantung paling & $3(6,4)$ \\
ringan Mandiri total & $15(31,9)$ \\
\end{tabular}

Mobilisasi adalah pergerakan yang memberikan kebebasan dan kemandirian bagi seseorang. Mobilisasi adalah pusat untuk berpartisipasi dalam kehidupan dan juga untuk menikmati kehidupan (Stanley dan Beare, 2006). Mobilisasi membutuhkan peran sistem musculoskeletal, kardiovaskuler, respirasi, saraf, alat indra, dan fungsi organ lainnya (Anggraini, 2018). Kemampuan mobilisasi lansia emmpengaruhi kemampuan mereka melakukan aktivitas sehati - hari. Lansia di UPT PSTW memiliki kemampuan mobilisasi mandiri. 
Gambar 1 Kemampuan Mobilisasi Lansia Hipertensi Di UPT PSTW

Bondowoso

\section{Kemampuan Mobilisasi n (\%)}

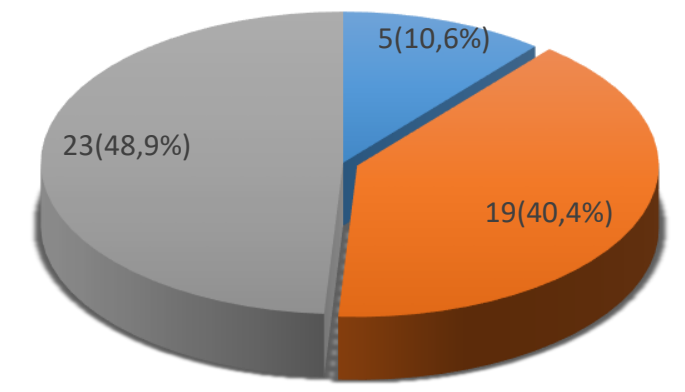

- Ketergantungan $\quad$ Parsial/ Butuh banuan $\square$ Mandiri

Berdasarkan pengukuran tingkat banyak responden mereka membutuhkan mobilisasi pada lansia di UPT PSTW bantuan untuk beraktivitas, baik bantuan Bondowoso didapatkan jumlah dari perawat maupun bantuan alat terbanyak lansia memiliki kemampuan mobilisasi. sehingga dapat ditarik mobilisasi mandiri (49,8\%). Hasil ini kesimpulan bahwa multiple disease lebih rendah dari pada hasil penelitian Anggarani (2018) yang menunjukkan dapat mempengaruhi kemandirian lansia dalam mobilisasi.

tingkat mobilisasi lansia di panti wredha St.Yosef Jelidro yang tergolong mandiri Tingkat kemampuan mobilisasi lansia $(77,8 \%)$. Hal ini dimungkinkan karena hipertensi yang tergolong parsial atau lansia memiliki diagnosa sekunder lebih dari satu penyakit sebanyak $(53,2 \%)$. membutuhkan bantuan didapatkan sebanyak (40,4\%). Hasil tersebut lebih Hasil ini didukung oleh penelitian yang tinggi dari pada hasil penelitian menyebutkan bahwa lansia dengan sebelumnya yang mendapatkan lansia penyakit kardiovaskular yang disertai parsial sebanyak (13,9\%). Kemungkinan penyakit metabolic dan secara hal ini disebabkan oleh adanya gangguan bersamaan mengalami penyakit gaya berjalan yang tidak teratur pada neurologis signifikan berhubungan dengan kejadian jatuh berulang (Ozturk dkk., 2017). Selain itu dalam penelitian tersebut menyebutkan bahwa cukup lansia hipertensi (42,6\%). Terdapat penelitian yang menyebutkan bahwa penyakit kardiovaskular dapat menimbulkan keterbatasan mobilisasi 
pada lansia (Welmer dkk., 2013).

berdampak pada keseimbangan, gaya

Didukung pula dengan penelitian berjalan dan risiko jatuh (Acar dkk., terdahulu bahwa hipertensi berkaitan dengan perlambatan kecepatan berjalan dan penurunan kecepatan berjalan yang lebih tinggi dalam Studi Tiga Kota Prancis (Welmer dkk., 2013). Oleh karena itu, dengan adanya gangguan dalam gaya berjalan lansia hipertensi mempengaruhi tingkat mobilitas lansia serta kemampuan mereka dalam melakukan aktivitas sehari - hari.

Sebagian kecil lansia hipertensi tergolong ketergantungan dalam mobilisasi mereka $(10,6 \%)$, penelitian Acar dkk, 2015 menyebutkan bahwa hipertensi berdampak negatif terhadap kontrol keseimbangan lanjut usia yang menunjukkan bahwa peningkatan tekanan darah tidak hanya menyebabkan 2015). Akibatnya penurunan stabilitas postur dapat membatasi kemandirian pasien dan menyebabkan terjatuh cedera yang apabila terjadi berulang dapat meningkatkan kemungkinan ketergantungan atau imobilisasi (Uchmanowicz dkk., 2016). Lansia dengan usianya yang menua telah mengalami penurunan kemampuan fisik, jika lansia mengalami hipertensi maka akan semakin menyebabkan lansia mengalami penurunan keseimbangan tubuh yang berpengaruh pada kemandirian dalam mobilisasi. Karena kemungkinan tersebut maka diperlukan latihan untuk meningkatkan keseimbangan tubuh agar kekuatan otot membaik dan lansia mampu melakukan aktivitasnya secara mandiri. penyakit kardiovaskular, tetapi juga

Gambar 2 Kategori Risiko Jatuh pada Lansia Hipertensi di UPT PSTW Bondowoso

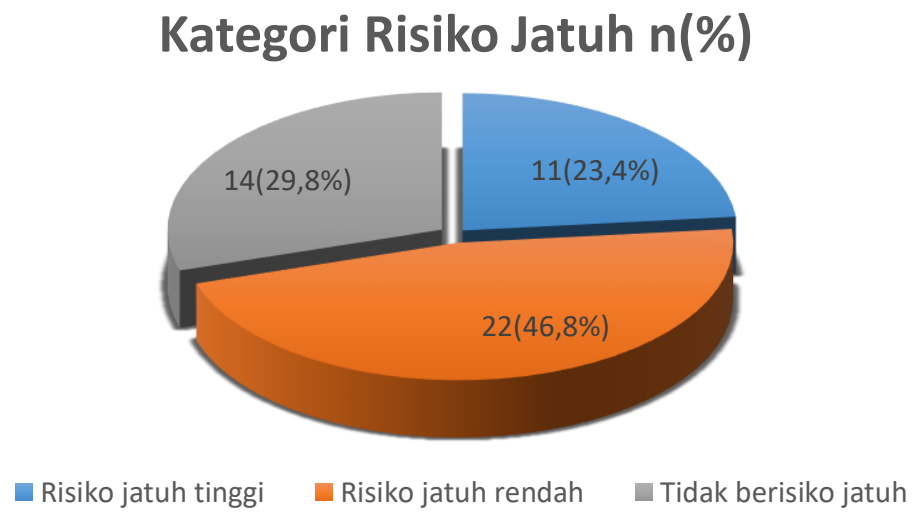


Berdasarkan hasil analisa data lansia hipertensi di UPT PSTW Bondowoso didapatkan sebagian besar lansia memiliki risiko jatuh rendah $(46,8 \%)$. Hasil ini lebih tinggi dari hasil penelitian Ramlis dkk. (2017) yang mendapatkan lansia berisiko jatuh rendah sebanyak (30\%). Rendahnya angka kejadian jatuh pada lansia hipertensi tersebut karena UPT PSTW Bondowoso berupaya meningkatkan kemampuan fisik lansia dengan gaya hidup aktif. UPT PSTW Bondowoso menjadwalkan senam rutin untuk lansia setiap minggu. Kegiatan ini dapat diikuti seluruh lansia yang mampu. Selain itu tersedianya bed rail pada tempat tidur lansia dengan keterbatasan gerak, permukaan lantai yang terjaga kebersihannya sehingga mencegah lansia terpeleset serta penerangan yang cukup.

Lansia hipertensi yang berisiko jatuh tinggi di UPT PSTW Bondowoso terdapat sebanyak $(23,4 \%)$, hasil penelitian ini lebih rendah dari pada penelitian sebelumnya yang mendapatkan risiko jatuh tinggi sebanyak (58,3\%) (Rudy dan Setyanto, 2019). Kemungkinan hal ini disebabkan oleh riwayat jatuh yang pernah dialami lansia. Didukung dengan penelitian lansia cenderung menunjukkan gelaja multiple risk factors yang tidak dapat dihindarkan baik dari penyakit-penyakit akibat lanjut dari gangguan muskuloskletal maupun penyakit yang lainnya (Poudal, Neupane \& Lopchan, 2014 dalam Yan dkk., 2019). Kondisi ini muncul akibat dari masa penuaan sehingga memicu imobilitas yang tinggi dan kejadian jatuh berulang pada lansia (Yan dkk., 2019). Oleh karena itu, dengan penuaan yang dialami lansia dan penurunan sebagian besar sistem dalam tubuhnya akan menyebabkan lansia berisiko mengalami jatuh berulang kali.

Sebanyak $(29,8 \%)$ lansia di UPT PSTW Bondowoso tidak berisiko jatuh. Hasil ini lebih tinggi dari pada hasil penelitian Ramlis (2017), angka lansia yang tidak berisiko jatuh pada lansia di BPPLU Kota Bengkulu sebanyak (25\%). Hal ini kemungkinan karena lansia di UPT PSTW Bondowoso melakukan latihan aktivitas fisik senam rutin setiap minggu. Didukung dengan penelitian sebelumnya yang menyebutkan bahwa kesehatan dapat dicapai dengan berolahraga secara rutin sesuai dengan keadaan fisik lansia sehingga menjadikan lansia sebagai individu yang mandiri, sehat dan tetap aktif (Kurnianto dkk., 2015). Oleh 
karena itu, lansia akan mencapai kemandirian mereka dan mencegah jatuh dengan olahraga rutin.

UPT PSTW Bondowoso telah melakukan berbagai upaya untuk mempertahankan dan menopang kemandirian lansia dengan adanya jadwal kegiatan senam rutin setiap minggu dan memberikan alat bantu berjalan berupa tongkat pada beberapa lansia dengan kesulitan berjalan serta penyediaan bedrail bagi lansia yang ketergantungan untuk meminimalisir jatuh. Lansia dengan risiko jatuh rendah sampai risiko jatuh tinggi masih mampu melakukan sebagian aktivitas sehari hari mereka, sehingga perlunya memperhatikan keadaan lingkungan untuk menyesuaikannya dengan keamanan lansia saat beraktivitas.

Tabel 2. Analisa hubungan kemampuan mobilisasi dan risiko jatuh pada lansia hipertensi

\begin{tabular}{cccccc} 
Kemampuan & \multicolumn{3}{c}{ Risiko Jatuh } & $\mathbf{X}^{2}$ & P value \\
\cline { 2 - 5 } Mobilisasi & Risiko & Risiko & Tidak & & \\
& tinggi n & rendah & berisiko n & & \\
& $(\%)$ & n(\%) & $(\%)$ & & \\
Ketergantungan & $10(21,3 \%)$ & $12(25,5 \%)$ & $2(4,3 \%)$ & 14,674 & 0,001 \\
- butuh bantuan & & & & & \\
Mandiri & $1(2,1 \%)$ & $10(21,3 \%)$ & $12(25,5 \%)$ & &
\end{tabular}

Hal tersebut merupakan syarat mendasar untuk lingkungan yang fungsional, salah satu yang dapat mendukung kemudahan lansia untuk berpindah yaitu tersedianya handrail (pegangan tangan) pada jalur perpindahan dan area kamar mandi, dapur serta tangga (Devi, 2016). Tangga dan ramp untuk area panti yang menanjak agar lansia tidak terpeleset (Bangngu dkk., 2018). Tempat tidur yang sesuai seharusnya memiliki pagar atau penyangga (bedrail) disampingnya agar menjegah terjatuh ketika tidur dan membantu lansia naik turun dari tempat tidur (Shanahan, 2011; Bangngu dkk., 2018). Dengan adanya rekomendasi ini diharapkan institusi memperhatikan lagi keamanan lingkungan bagi lansia sebagai penghuni panti. 
Hasil uji statistik didapatkan terdapat hubungan antara kemampuan mobilisasi dengan risiko jatuh pada lansia hipertensi di UPT PSTW Bondowoso ( $p$ value $=0,001$ ). Hasil penelitian ini sesuai dengan penelitian sebelumnya yang menggunakan uji statistik Spearman Rho dengan $p$ value 0,018 dan dinyatakan bahwa jenis kelamin dan mobilitas mempunyai hubungan dengan risiko jatuh (Anggraini, 2018). Hal tersebut kemungkinan disebabkan oleh keseimbangan lansia dalam berjalan sehingga gaya berjalan lansia tidak teratur atau tidak aman. Lansia di UPT PSTW Bondowoso memiliki gaya berjalan yang tidak teratur $(42,6 \%)$. Lansia dengan gangguan keseimbangan menggunakan alat bantu ketika berjalan (46,8\%), alat bantu tersebut berupa tongkat dan kruk, serta lansia berpegangan pada benda - benda disekitarnya seperti meja, kursi dan benda - benda lain didekatnya. Saat seorang tumbuh, pola aktivitas berubah, massa otot berkurang dan postur serta komposisi tulang berubah (Potter dan Perry, 2017). Perubahan tersebut mempengaruhi keseimbangan lansia dalam berjalan, dan ketika keseimbangan lansia menurun akan menimbulkan risiko jatuh pada lansia.
Hubungan kuat antara kemampuan mobilisasi yang baik atau dapat dikatakan lansia mandiri dapat menjauhkan lansia terhadap risiko jatuh, dan sebaliknya apabila kemampuan mobilisasi lansia menurun atau bahkan lansia tidak mampu melakukan mobilisasi tanpa bantuan orang lain maka akan meningkatkan risiko jatuh yang mungkin dialaminya. Lansia perlu diperhatikan terkait latihan fisik khususnya latihan keseimbangan guna mempertahankan kemampuan mobilisasi yang optimal.

Penelitian ini menunjukkan hasil kemampuan - kemampuan lansia dalam melakukan mobilisasi seperti kemampuan lansia berbaring, duduk, berdiri, berjalan dan meraih suatu benda. Rata - rata kemampuan mobilisasi lansia adalah mandiri. Intensitas aktivitas fisik lansia menurun seiring penuaan yang dialaminya. Penurunan aktivitas fisik dan imobilisasi dapat menyebabkan lansia mengalami penurunan kekuatan otot (Potter dan Perry, 2017). Kemampuan mobilisasi dikaitkan dengan aktivitas fisik yang dilakukan lansia. Lansia lebih sering duduk berdiam dan berbaring dari pada melakukan aktivitas fisik, hal tersebut 
dimungkinkan oleh kurangnya pengertahuan dan minat lansia terhadap latihan fisik. Lansia seharusnya melakukan aktivitas fisik setidaknya 30 menit setiap hari dalam seminggu (Kurnianto dkk., 2015).

Lansia dalam penelitian ini memiliki risiko jatuh rendah dan sebagian besar mampu melakukan aktivitas sehari - hari mereka dengan mandiri. Untuk itu, lansia mampu melakukan aktivitas fisik guna mempertahankan kondisi kesehatan mereka di usia tua. Aktivitas fisik (physical activity) didefinisikan sebagai semua bentuk kegiatan atau pergerakan tubuh yang menyebabkan pengeluaran energi, seperti melakukan pekerjaan rumah tangga, berbelanja, berkebun, maupun berolah raga (Dewi, 2018). Setiap aktivitas fisik membutuhkan keseimbangan, dengan program latihan fisik keseimbangan atau olahraga yang mengandung unsur keseimbangan seperti berenang, senam, Taichi dll, dapat mengurangi resiko lansia jatuh, sehingga kemungkinan terjadinya cidera, fraktur bahkan kematian bisa diminimalisir, dan harapan hidup atau kesehatan atau kebugaran lansia tetap terjaga (Supriyono, 2015).
Aktivitas fisik yang direkomendasikan oleh WHO yang bertujuan untuk memperbaiki kesehatan kardiorespirasi dan kebugaran otot, kesehatan tulang, dan menurunkan risiko Penyakit Tidak Menular (PTM) serta depresi adalah sebagai berikut. Pertama, orang dewasa yang berusia 18-64 tahun hendaknya melakukan aktivitas fisik aerobik level sedang minimal 150 menit dalam seminggu atau melakukan setidaknya 75 menit aktivitas fisik aerobik level tinggi dalam seminggu, atau yang setara dengan kombinasi aktivitas fisik level sedang hingga tinggi. Kedua, aktivitas aerobik hendaknya dilakukan setidaknya dalam durasi 10 menit. Ketiga, untuk menambah manfaatnya bagi kesehatan, hendaknya aktivitas fisik tersebut ditingkatkan pada aktivitas fisik aerobik level sedang menjadi 300 menit per minggu, tercapainya aktivitas fisik aerobik level tinggi 150 menit perminggu atau yang setara dengan kombinasi keduanya. Keempat, aktivitas penguatan otot hendaknya dilakukan dengan melibatkan grup-grup otot utama dalam 2 hari atau lebih perminggu (Dewi, 2018).

Di samping faktor - faktor internal terkait mobilisasi dan risiko jatuh, faktor 
eksternal juga cukup memberikan pengaruh terhadap kemampuan mobilisasi lansia. Diantaranya yaitu, kesesuaian jumlah perawat yang memfasilitasi perawatan lansia setiap harinya, keamanan lingkungan yang meliputi lantai yang tidak licin, handrail dalam kamar mandi dan permukaan yang miring serta pencahayaan yang baik, alat bantu jalan dan jadwal kegiatan yang diberikan panti sosial. Apabila faktor faktor tersebut terpenuhi maka akan menopang aktivitas lansia sehari - hari dan meminimalkan risiko jatuh yang mungkin ditimbulkan.

Berdasarkan ulasan diatas dapat disimpulkan bahwa lansia dengan penurunan sistem muskuloskeletal harus mampu modifikasi gaya hidup agar dapat menurunkan efek penuaan yang dialaminya dan isntitusi perlu memperhatikan keadaan lingkungan serta menyesuaikan jumlah perawat dengan perawatan yang dibutuhkan lansia (Stanley dan Beare, 2006; Devi, 2016) . Sehingga lansia dapat terfasilitasi dalam perawatan dan latihannya serta terhindar dari kondisi imobilisasi. Terutama untuk melakukan aktivitas fisik, manfaat latihan fisik terbukti mengurangi tekanan darah dan kolesterol, meningkatkan resistensi insulin, mengurangi berat badan, memperkuat tulang, dan mengurangi jatuh.

\section{SIMPULAN}

Lansia dengan hipertensi yang tinggal di UPT PSTW Bondowoso sebagian besar mandiri dalam melakukan mobilisasi $(49,8 \%)$ dan sebagian besar lansia di UPT PSTW Bondowoso memiliki risiko jatuh yang rentangnya rendah $(46,8 \%)$. Hasil uji statistik menyatakan terdapat hubungan antara kemampuan mobilisasi dengan risiko jatuh pada lansia hipertensi di UPT PSTW Bondowoso ( $p$ value $=0,001)$. Karena itu, sangat penting bagi lansia dengan hipertensi untuk melakukan aktivitas fisik guna meningkatkan keseimbangan tubuh sehingga mampu mobilisasi secara mandiri dan menurunkan kemungkinan jatuh.

\section{SARAN}

Diharapkan penelitian selanjutnya dapat lebih spesifik membahas terkait bagaimana kemampuan mobilisasi pada lansia dengan hipertensi dan membandingkannya pada lansia yang tidak mengalami hipertensi serta hubungan masing masing kelompok 
dengan risiko jatuh.

\section{UCAPAN TERIMA KASIH}

Terimakasih kepada kelompok riset Keperawatan Gerontik Universitas Jember Helathy and Wellness of Elderly Studies yang telah membantu dalam proses penyelesaian penelitian ini.

\section{DAFTAR RUJUKAN}

Acar, S., İ. Demirbüken, C. Algun, M. Malkoç, dan N. Tekin. 2015. Is Hypertension A Risk Factor For Poor Balance Control In Elderly Adults? Journal of Physical Therapy Science. 27(3):901-904.

Anggraini, A. P. M. 2018. Kemampuan Mobilitas Merupakan Faktor Risiko Jatuh Terkuat Pada Lansia. Jurnal Penelitian Kesehatan. 5(2):72-78.

Bangngu, H. C., D. Puspita, dan D. N. Gasong. 2018. Evaluasi Keamanan Lingkungan Bagi Lansia Yang Tinggal Di Panti Wredha Salib Putih Salatiga. Prosiding Seminar Nasional Mahasiswa Unimus. 1:91-98.

Black, J. dan J. Hawks. 2013. Keperawatan Medikal Bedah (3Vol Set) 8th Edition Manajemen Klinis untuk Hasil yang Diharapkan. Singapore: Elsevier Ltd.

Devi, E. 2016. POLA Penataan Ruang Panti Jompo Berdasarkan Aktivitas dan Perilaku Penghuninya. Jurnal Arteks. I(1):31-48.
Dewi, S. K. 2018. Level Aktivitas Fisik dan Kualitas Hidup Warga Lanjut Usia Physical Activity Level and Quality Of Life Of The Elderly. Jurnal MKMI. 14(3):241-250.

Ediawati, E. 2012. Hubungan Tingkat Kemandirian Dalam Activity Daily Living (ADL) dan Risiko Jatuh Pada Lansia Di Panti Sosial Tresna Werdha Budi Mulia 01 dan 03 Jakarta Timur. Depok: Fakultas Ilmu Keperawatan.

Gangavati, A., I. Hajjar, L. Quach, R. N. Jones, D. K. Kiely, G. Peggy, dan L. A. Lipsitz. 2012. Hypertension, Orthostatic Hypotension, and The Risk Of Falls In A CommunityDwelling Elderly Population: The Maintenance of Balance, Independent Living, Intellect, and Zest In The Elderly of Boston Study. The American Geriatrics Society. 59(3):383-389.

Kemenkes RI. 2017. Sebagian Besar Penderita Hipertensi Tidak Menyadarinya.

http://sehatnegeriku.kemkes.go.id/ baca/rilismedia/20170517/3220892/sebagia n-besar-penderita-hipertensi-tidakmenyadarinya/. (diakses 19 September 2019)

Kementrian Kesehatan RI. 2016. Situasi Lanjut Usia (LANSIA) Di Indonesia. Jakarta Selatan: Kemenkes RI. 16.

Kurnianto, D., P. Ilmu, K. Pps, A. Makalah, P. Lansia, dan P. Apa. 2015. Menjaga Kesehatan Di Usia Lanjut. Jorpres. 11(2):19-30. 
Murtiani, N. dan H. Suidah. 2019. Pengaruh Pemberian Intervensi 12 Balance Exercise terhadap Keseimbangan Postural Pada Lansia. Jurnal Keperawatan. 12(1):42-52.

Ozturk, T. C., R. Ak, E. Unal Akoglu, O. Onur, S. Eroglu, dan M. Saritemur. 2017. Factors Associated with Multiple Falls Among Elderly Patients Admitted to Emergency Department. International Journal of Gerontology. 11(2):85-89.

Potter, A. P. dan A. G. Perry. 2010. Fundamentals of Nursing: Fundamental Keperawatan. Edisi 7. Jakarta: Salemba Medika.

Potter, A. P. dan A. G. Perry. 2017. Fundamental Keperawatan, Edisi 7 Buku 3. Edisi 7. Singapore.

Rudy, A. dan R. B. Setyanto. 2019. Analisis Faktor yang Mempengaruhi Risiko Jatuh Pada Lansia. 5:52-56.

Seke, P. A., H. J. Bidjuni, dan J. Lolong. 2016. Hubungan Kejadian Stres dengan Penyakit Hipertensi Di Balai Penyantunan Lanjut Usia Senjah Cerah Kecamatan Mapanget Kota Manado. E-Journal Keperawatan. 4(June):1-5.

Smith, R. 1994. Validation And Reliability Of The Elderly Mobility Scale. Physiotherapy (United Kingdom). 80(11):744-747.

Stanley, M. dan P. G. Beare. 2006. Gerontological Nursing: A Health Promotion/ Protection Approach. Philadelphia: The F.A. Davis Company.
Supriyono, E. 2015. Aktivitas Fisik Keseimbangan Guna Mengurangi Resiko Jatuh Pada Lansia. Jurnal Olahraga Prestasi. 11(2):91-101.

Susanto, T. 2013. Keperawatan Gerontik. Edisi 1. Jember: UPT Penerbitan Unej.

Uchmanowicz, I., A. Chudiak, J. Polańska Beata, dan R. Gobbens. 2016. Detailed Relationship Between The Pattern Of Blood Pressure Change During The Valsalva Maneuver and The Degree Of Orthostatic Hypotension During The Head-Up Tilt Test In Patients with Orthostatic Intolerance: A Retrospective CaseControl Study. Medicine (United States). 95(19):102-107.

Uda, H. D. H., Muflih, dan A. E. A. Thomas. 2016. Latihan Range of Motion Berpengaruh Terhadap Mobilitas Fisik Pada Lansia Di Balai Pelayanan Sosial Tresna Werdha Unit Abiyoso Yogyakarta. Journal Ners And Midwifery Indonesia. 4(3):169-177.

Welmer, A. K., S. Angleman, E. Rydwik, L. Fratiglioni, dan C. Qiu. 2013. Association Of Cardiovascular Burden With Mobility Limitation Among Elderly People: A Population-Based Study. PLoS ONE. 8(5):1-7.

WHO. $2018.2 \quad$ Falls. https://www.who.int/newsroom/fact-sheets/detail/falls. (diakses 22 september 2019) 
WHO. 2019. Hypertension. Yan, L. S., D. Octavia, dan W. Suweno. https://www.who.int/newsroom/fact-

sheets/detail/hypertension. (Diakses 19 september 2019) 2019. Pengalaman Jatuh dan Kejadian Imobilitas pada Kelompok Lanjut Usia. Jurnal Endurance: Kajian Ilmiah Problema Kesehatan. 4(1):150-161. 